\title{
A quick and efficient method to generate mammalian stable cell lines based on a novel inducible alphavirus DNA/RNA layered system
}

\author{
Alejandro Aranda $\cdot$ Jaione Bezunartea $\cdot$ \\ Erkuden Casales · Juan R. Rodriguez-Madoz • \\ Esther Larrea $\cdot$ Jesus Prieto $\cdot$ Cristian Smerdou
}

Received: 19 February 2014 / Revised: 15 April 2014 / Accepted: 17 April 2014 / Published online: 3 May 2014

(C) Springer Basel 2014

\begin{abstract}
We report a new method to generate highexpressing mammalian cell lines in a quick and efficient way. For that purpose, we developed a master cell line (MCL) containing an inducible alphavirus vector expressing GFP integrated into the genome. In the MCL, recombinant RNA levels increased $>4,600$-fold after induction, due to a doxycycline-dependent RNA amplification loop. The MCL maintained inducibility and expression during 50 passages, being more efficient for protein expression than a conventional cell line. To generate new cell lines, mutant LoxP sites were inserted into the MCL, allowing transgene and selection gene exchange by Cre-directed recombination, leading to quick generation of inducible cell lines expressing proteins of therapeutic interest, like human cardiotrophin-1 and oncostatin-M at several $\mathrm{mg} / \mathrm{l} / 24 \mathrm{~h}$. These
\end{abstract}

Electronic supplementary material The online version of this article (doi:10.1007/s00018-014-1631-2) contains supplementary material, which is available to authorized users.

A. Aranda $\cdot$ J. Bezunartea

3P Biopharmaceuticals S.L., Polígono Mocholí, C/Mocholí 2,

31110 Noain, Spain

A. Aranda $\cdot$ E. Casales $\cdot$ J. R. Rodriguez-Madoz $\cdot$ E. Larrea $\cdot$

J. Prieto $\cdot$ C. Smerdou $(\bowtie)$

Division of Hepatology and Gene Therapy, Center for Applied Medical Research, University of Navarra, Pamplona, Navarra, Spain

e-mail: csmerdou@unav.es

Present Address:

A. Aranda

UFR des Sciences de la Santé Simone Veil, 2 Avenue de la

Source de la Bievre, 78180 Montigny-Le-Bretonneux, France

J. Prieto

Liver Unit, Clinica Universitaria de Navarra, CIBER-EHD,

Pamplona, Spain proteins contained posttranslational modifications, showed bioactivity, and were efficiently purified. Remarkably, this system allowed production of toxic proteins, like oncostatin-M, since cells able to express it could be grown to the desired amount before induction. These cell lines were easily adapted to growth in suspension, making this methodology very attractive for therapeutic protein production.

Keywords Stable cell lines $\cdot$ Alphavirus $\cdot$ Protein production · Inducible expression

\section{Introduction}

Mammalian cells have become the main system for production of recombinant proteins with clinical applications due to their capacity to produce proteins correctly folded and containing appropriate post-translational modifications [1]. Most mammalian stable cell lines are generated by genomic integration of the gene of interest using strong viral or cellular promoters/enhancers to drive expression. Selection of cell lines is usually achieved by inserting into the genome a second gene conferring a selective advantage, like resistance to an antibiotic or the ability to grow in specially formulated media. Non-viral gene transfer is usually the method of choice to generate stable cell lines for manufacturing purposes. Expression levels obtained with this method depend on a number of factors, which include transgene integration position, number of integrations/cell, and variations between individual cells. For this reason, generation of a high producer cell line usually requires the screening of hundreds of cell clones, which is a laborious and time-consuming task. In addition, the growth rate of individual clones has to be carefully monitored, since only the combination of fast growth and high productivity will 
make a cell line suitable for scale-up and manufacturing. Moreover, proteins that diminish cell growth or are toxic to cells are difficult to produce with these systems.

An alternative way to produce recombinant proteins in mammalian cells is the use of viral vectors. Some advantages of these vectors are their efficacy of entry into cells as well as their self-amplifying nature, which can lead to very high expression levels. Among the viral vectors that have been most commonly used for protein production are adenoviruses, poxviruses, and alphaviruses [2]. These systems are usually transient, due to the cytopathic nature of viruses, but allow production of high levels of recombinant protein.

Alphavirus vectors are based on RNA replicons in which the viral structural genes have been deleted and substituted by a heterologous gene [3-5]. The alphavirus replicon contains an open reading frame (ORF) coding for the viral replicase (Rep) at its $5^{\prime}$ end, which is translated upon transfection of RNA into eukaryotic cells. Rep can copy the vector RNA into a negative strand RNA that is used as a template to make more replicon molecules [6]. Rep can also recognize an internal sequence in the negative strand RNA, or subgenomic promoter, from which it will synthesize a subgenomic RNA that will be translated to produce the heterologous protein at very high levels. Replication of alphavirus vectors is cytopathic for most mammalian cells, leading to cell death by apoptosis [7-9]. Despite their transient nature, these vectors have been extensively used for protein production due to their rapid pattern of protein expression [10].

In the last years, a number of mutations have been identified within alphavirus Rep sequences that can render these vectors less cytopathic, allowing more prolonged expression of recombinant proteins in cell culture. These mutant vectors have been developed from alphaviruses that include Sindbis virus (SIN) [11, 12], Semliki Forest virus (SFV) [12-16], and Venezuelan Encephalitis virus (VEE) [17]. Some of these mutant vectors can be used to generate RNA-based stable mammalian cell lines if a selection gene is included in the replicon [18]. We have previously shown that a noncytopathic mutant derived from SFV (ncSFV) containing mutations P718T and R649H in the nsp2 subunit of Rep and a gene conferring resistance to puromycin (pac) can be used to select cells that maintain the RNA replicon after many passages [13]. Using this strategy, we were able to generate stable cell lines producing high levels of human therapeutic proteins, like insulinlike growth factor I (IGF-I) and cardiotrophin-1 (CT-1), by including their genes after a second subgenomic promoter or by fusing them at the carboxy-terminal end of pac, using as a linker the sequence coding for foot-and-mouth disease virus (FMDV) 2A autoprotease [19]. Despite the fact that these cell lines showed a reasonable stability, in some cases expression levels decreased after 5-10 passages. In addition, since these cell lines rely on continuous replication of an RNA replicon and since Rep does not seem to contain proof-reading activity, mutations could accumulate in sequences which are not under selective pressure, like those coding for the recombinant protein. Finally, constitutive expression of recombinant proteins in these cells prevents their use for the production of toxic proteins at biopharmaceutical levels.

In order to solve these problems we have generated a new mammalian stable cell line system containing the ncSFV cDNA sequence integrated into the genome and under the transcriptional control of a doxycycline-inducible promoter. This master cell line (MCL), which carries GFP as reporter gene, showed a very high inducibility and stability and was able to reach high expression levels. In order to generate new cell lines in a quick way from the MCL, we also designed a strategy based on switching GFP by the desired transgene using Cre-mediated recombination. This allowed the generation of new cell lines expressing human therapeutic proteins like CT-1, a protein with potent hepatoprotective effects [20], at levels similar to those provided by cell lines generated with ncSFV RNA [21]. In addition, these cells were able to express high levels of toxic proteins like oncostatin M (OSM), a protein that has shown both antiviral and immunostimulatory properties [22], since cells able to express OSM could be grown to the desired amount before being induced. The fact that these cells can be easily adapted to growth in suspension cultures make them very attractive for production of therapeutic human recombinant proteins.

\section{Materials and methods}

\section{Cell culture}

BHK-21 cells (ATCC: CCL-10) were cultured in BHK-21 Glasgow MEM (Gibco BRL, UK) supplemented with $5 \%$ FBS, $10 \%$ tryptose phosphate broth, $2 \mathrm{mM}$ glutamine, $20 \mathrm{mM}$ HEPES, $100 \mu \mathrm{g} / \mathrm{ml}$ streptomycin and $100 \mathrm{IU} / \mathrm{ml}$ penicillin (BHK complete medium). Huh7 and HepG2 (ATCC-HB8065) cells were incubated in Dulbecco's modified Eagle's medium (Invitrogen, Carlsbad, CA, USA) supplemented with $10 \%$ FBS, $2 \mathrm{mM}$ glutamine, $100 \mu \mathrm{g} /$ $\mathrm{ml}$ streptomycin and $100 \mathrm{IU} / \mathrm{ml}$ penicillin. BHK cell lines adapted to growth in suspension were cultured in SMEM (Sigma, St. Louis, MO, USA) supplemented with up to $10 \%$ FBS, $10 \%$ tryptose phosphate broth, $2 \mathrm{mM}$ glutamine, $20 \mathrm{mM}$ HEPES, $100 \mu \mathrm{g} / \mathrm{ml}$ streptomycin, $100 \mathrm{IU} /$ $\mathrm{ml}$ penicillin, and $0.1 \%$ pluronic acid F-68 (Gibco BRL, UK) (SMEM complete medium) or in EX-CELL CD CHO, supplemented with $10 \%$ tryptose phosphate broth, 
$2 \mathrm{mM}$ glutamine, $20 \mathrm{mM}$ HEPES, $100 \mu \mathrm{g} / \mathrm{ml}$ streptomycin, $100 \mathrm{IU} / \mathrm{ml}$ penicillin, and $0.1 \%$ pluronic acid F-68 (serum-free medium). Transfection of BHK cells was performed using Lipofectamine reagent (Gibco BRL, Rockville, MD, USA) diluted in Opti-MEM reduced-serum medium (Gibco-BRL) following the manufacturer's recommendations. For selection of cell lines, culture media was supplemented with hygromycin B (Invitrogen), neomycin (G418, Gibco BRL), or puromycin (Sigma, St. Louis, MO, USA) at 250,750 , and $5 \mu \mathrm{g} / \mathrm{ml}$, respectively, $24 \mathrm{~h}$ after transfection. Determination of the doubling time of cell lines was performed by counting the number of viable cells after trypsinization and Trypan blue staining at different time points during a period of $72 \mathrm{~h}$. In the case of suspension cultures, cells were directly stained and counted. For induction studies, adherent cells were seeded at a density of $5 \times 10^{5}$ cells/well in six-well tissue culture plates and incubated in the presence of DOX for a period of 96-120 h. In the case of suspension cells, DOX was added directly to a culture containing $2.5 \times 10^{5}$ cells $/ \mathrm{ml}$ and incubation in the presence of inducer proceeded for up to 10 days.

Plasmid constructs

\section{General considerations}

All PCR fragments were amplified by using Pfu or Pfu Turbo (Invitrogen) and the primers indicated in
Supplementary Table 1. After purification by Gel Extraction Kit (Qiagen), fragments were adenylated, cloned into the pGEM-T-easy vector (Promega), sequenced, and subcloned into the final plasmid using the indicated restriction sites.

pPGK-TA-ires-Hyg

The hygromycin resistance gene was amplified by PCR with primers 1 and 2 using the pTK-Hyg plasmid (Clontech) as template and cloned into pIRES (Clontech) downstream of the encephalomyocarditis virus (ECMV) internal ribosome entry site (IRES) sequence using XmaI and NotI sites, generating pIRES-Hyg. The rtTAs2M2 [23] gene was placed under the control of the PGK promoter and fused to the IRES-Hyg cassette from pIRES-Hyg using XhoI and MluI sites, generating the pGK-TA-ires-Hyg plasmid (Fig. 1).

\section{piPalb-GFP}

To obtain a fusion between the first $85 \mathrm{nt}$ corresponding to the $5^{\prime}$-UTR of the SFV genome (5'-UTR-SFV) and GFP, a crossover PCR was performed. A first PCR was set up by using pSFV1 [3] as a template and primers 3 and 4 . A second PCR was performed with primers 5 and 6, using pCMV-GFP (Clontech) as a template. The resulting fragments were purified, mixed, and used as a template for a

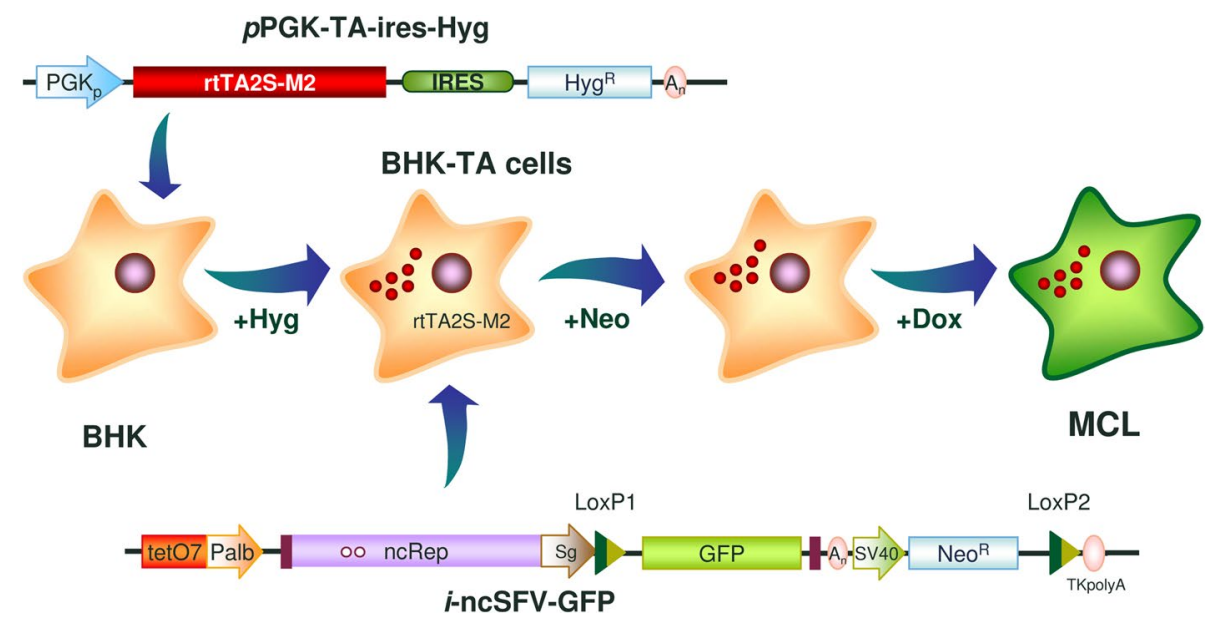

Fig. 1 Generation of a master cell line (MCL) harboring an inducible noncytopathic SFV vector expressing GFP. BHK cells were transfected with a plasmid constitutively expressing the rtTA2S-M2 transactivator linked to the hygromycin resistance gene $\left(\mathrm{Hyg}^{\mathrm{R}}\right)$ by an IRES element (pPGK-TA-ires-Hyg, upper diagram). After selection with hygromycin, a clone was transfected with a plasmid containing the inducible noncytopathic SFV vector expressing GFP (i-ncSFVGFP) and a neomycin resistance gene $\left(\mathrm{NeO}^{\mathrm{R}}\right.$ ) (lower diagram). In this vector, the ncSFV sequence is under the transcriptional control of a minimal albumin promoter (Palb) fused to a tetracycline responsive element (tetO7), whereas the GFP sequence is located downstream of the SFV subgenomic promoter $(\mathrm{Sg})$. Mutant LoxP sites were cloned upstream of the GFP sequence and downstream of $\mathrm{Neo}^{\mathrm{R}}$, respectively (LoxP1 and LoxP2). Cells were selected with neomycin, cloned by terminal dilution and analyzed in terms of inducibility, GFP expression, and absence of leakage, to obtain the i-ncSFV-LoxP-GFP MCL. PGK , phosphoglycerate kinase promoter; ncRep, non cytopathic SFV Rep; SV40, SV40 promoter; An, SV40 polyadenylation sequence; TKpolyA, Herpes simplex virus thymidine kinase polyadenylation sequence 
crossover PCR with primers 3 and 6 , in order to obtain a 1,057-bp fragment containing 5'-UTR-SFV-GFPSV40PolyA. To place this fragment downstream of tetO7pAlb promoters of different lengths, a subsequent crossover PCR was set up. First, fragments containing different promoters were generated by using primer 7 in combination with primer 8, 9, and 10, respectively, using AAV8-Tet bidir $^{-}$ Alb- $\mathrm{CMV}_{\mathrm{m}}$-luc as template, kindly provided by Dr. Gloria Gonzalez-Aseguinolaza (CIMA, Spain) [24]. Crossover PCRs were performed by using purified fragments in combination with fragment $5^{\prime}$ UTR-SFV-GFP-SV40PolyA and primers 7 and 6. All PCR fragments were cloned into pGEM-T-easy, generating plasmids piPalb-172-GFP, piPalb-173-GFP, and piPalb-174-GFP, which contain the 5'-UTR-SFV sequence placed at 172, 173, and 174 nucleotides downstream from the beginning of the minimal Palb promoter [25], respectively.

\section{$i$-ncSFV-GFP}

In a first step, a 2,078-bp fragment containing the $\mathrm{Neo}^{\mathrm{R}}$ ORF followed by the thymidine kinase-polyA signal from Herpes simplex virus and the pUC origin of replication (neo-polyA-ori) was amplified by PCR from the pBK-TSFV-1 [7] vector using primers 11 and 12 , and cloned into pGEM-T-easy to obtain the pGEM-A1 plasmid. In a second step, a fusion between the minimum tetO7-Palb promoter that contains 174 nucleotides of Palb and a $5^{\prime}$ fragment of SFV that includes the first $280 \mathrm{nt}$ of the replicon was obtained by crossover PCR. The first PCR was performed with primers 7 and 10 using piPalb-174-GFP as a template. The second PCR was performed with primers 13 and 14, using pBK-T-SFV-1 as a template. The two fragments were purified, mixed, and used as a template with primers 7 and 14. This PCR product was digested with NsiI and EcoRV and the obtained 796-bp fragment was subcloned into pGEM-A1 vector digested with the same enzymes, generating a plasmid in which tetO7-Palb-5'UTR-SFV was linked to the neo-polyA-ori sequence (pGEM-A2). This plasmid was digested with SfiI and EcoRV and the 2,874-bp fragment was subcloned into the same sites of pBK-T-ncSFV-1, which derives from pBK-T-SFV-1 [7] and contains P718T and R649H mutations in the nsp2 subunit of the Rep [13]. In this way, we generated i-ncSFV in which the sequence of the full ncSFV replicon is downstream of the inducible tetO7-Palb promoter and is followed by $\mathrm{NeO}^{\mathrm{R}}$ downstream of the SV40 promoter. To introduce the LoxP2 site, a 1,106-bp fragment including this sequence was generated by PCR using primers 11 and 15 and pBK-T-SFV- 1 as a template. This fragment was digested with SpeI and AvrII and subcloned into AvrII sites of i-ncSFV. On the other hand, a DNA fragment containing the GFP gene was generated by PCR using primers 16 and 17, from pCMV-GFP as a template, and subcloned into BamHI and XmaI sites of i-ncSFV, downstream of the SFV subgenomic promoter. Finally, a synthetic LoxP1, produced by hybridization of primers 18 and 19 was inserted into the BamHI site to generate i-ncSFV-GFP vector (Fig. 1).

\section{$i G F P$ (control)}

The i-ncSFV-GFP vector was digested with PacI and SpeI to delete the $3^{\prime}$-UTR-SFV, filled in with Klenow and T4 DNA polymerase, respectively, and ligated with T4 DNA ligase. Using this construction, a cassette of $3,687 \mathrm{pb}$ containing LoxP1-GFP-SV40PolyA-SV40Prom-neoR-LoxP2TK-PolyA was generated by PCR using primers 20 and 21, and subcloned into piPalb174-GFP by digestion with NdeI and SpeI restriction enzymes.

\section{pShuttle-SFV and pShuttle-SFV-GOI}

The EF1 $\alpha$ promoter (EF1Pr) was amplified by PCR using primers 22 and 23 from AAV-Luc, kindly provided by Dr. Gloria Gonzalez-Aseguinolaza [26], obtaining a fragment of 1,182 bp that was subcloned into pBS-pac plasmid [27] with EcoRV and NotI restriction sites. In the newly generated plasmid (pBS-EF1-pac), pac expression is driven from EF1Pr. The sequence of LoxP3 followed by a multiple cloning site containing restriction sites BgIII, NruI, SacI, BlpI, and NdeI (MCS) was generated by hybridizing primers 24 and 25 and the 62-bp synthetic fragment obtained in this way was introduced into pBS-EF1Pr-pac upstream of the EF1Pr-pac sequence using a unique NdeI site, generating pBS-LoxP3-EF1-pac. A fragment containing 3'-UTR-SFV and SV40 PolyA sequences was amplified by PCR using primers 26 and 27 and pSFV1 as a template and subcloned between NdeI and PvuII restriction sites in pBS-LoxP3-EF1-pac. The SV40PolyA sequence at the $3^{\prime}$ end of pac was deleted by digestion with $\mathrm{NcoI}$ and BamHI followed by introduction of a LoxP4 site using a synthetic dimer obtained after hybridization of primers 28 and 29. An SV40 promoter sequence remaining from the original pBSpac was eliminated by digestion with EcoRV and PvuII followed by plasmid religation to finally obtain pShuttleSFV. pShuttle-SFV-Tomato was generated by insertion of the Tomato gene, previously amplified from pCAG-tdTOMATO-IRES-neo, kindly provided by Dr. Beatriz Pelacho (CIMA), with primers 30 and 31, into BglII and NdeI sites of pShuttle-SFV. To generate pShuttle-SFV-CT, the CT-1 gene was amplified from ncSFV-CT1 [21] by using primers 32 and 33, and the fragment obtained was inserted into BglII and NdeI sites into pShuttle-SFV. To generate pShuttle-SFV-OSM, the coding sequence of human OSM was first obtained by RT-PCR from a sample of CD40ligand stimulated dendritic cells using primers 34 and 35 . 
The amplified fragment was cloned into the pCR2.1-TOPO vector (Life Technologies, Grand Island, NY, USA) and verified by automatic sequencing in an ABI PRISM 310 Genetic Analyser (Applied Biosystems). In a second step, the OSM gene was amplified using primers 36 and 37, and the 671-bp fragment obtained was inserted into NruI and NdeI sites in pShuttle-SFV. The ORF that was cloned comprises the sequence coding for preprotrypsin signal peptide followed by a 6-His tag (included in oligonucleotide 36 ) and amino acids 1-221 of human mature OSM [28].

\section{Cloning of cells by terminal dilution}

Cells to be cloned were trypsinized, washed, resuspended in BHK complete medium to a final concentration of 5 cells $/ \mathrm{ml}$, distributed onto 96-well tissue culture plates by adding $100 \mu \mathrm{l}$ per well, and incubated for up to 4 weeks changing the medium every week. After a minimum of 2 weeks of incubation, wells containing a single cell colony were trypsinized, resuspended in medium, and sequentially expanded onto 24-well, six-well tissue culture plates, T25, and T75 tissue culture flasks. Cells of selected clones were frozen in freezing medium (10\% DMSO in FBS) and stored in liquid nitrogen. An average of 20 clones was selected for every parental cell culture.

\section{RT-PCR analysis}

Approximately $10^{6}$ cells were collected and total RNA was purified with TRI-Reagent (SIGMA) following the manufacturer's instructions. RNA was reverse-transcribed into cDNA using random primers (Promega) and SuperScript III RT (Invitrogen, Carlsbad, CA, USA). Quantitative RTPCR was carried out using Power SYBR Green PCR Master Mix (Bio-Rad, Hercules, CA, USA) and combinations of specific primers (Supplementary Table 1). For detection of specific replicon molecules harboring GFP, primers 38 and 39 were used, whereas replicon molecules carrying CT-1 and OSM were detected by PCR with primer 38 in combination with primers 40 and 37, respectively. On the other hand, correct exchange between neomycin and puromycin ORFs was assessed by combinations of TK-PolyA specific primer (primer 41) with primers 42 and 43, respectively. Rep was amplified by using primers 44 and 45 . When necessary, data were normalized by amplification of actin, using primers 46 and 47 .

\section{Analysis of RNA stability}

Master cell line cells from several passages were incubated during $120 \mathrm{~h}$ with $1.25 \mu \mathrm{g} / \mathrm{ml}$ DOX or without DOX, collected, pelleted by centrifugation, and total RNA was purified by TRI-Reagent (SIGMA). Total RNA was reverse-transcribed into cDNA as described above. The generated cDNAs were subjected to PCR with high-fidelity Pfu DNA polymerase (Stratagene, Cedar Creek, TX, USA) to amplify a fragment comprised of nucleotides 1-669 of the GFP gene, using primers 16 and 17. After purification, amplified DNA fragments were polyadenylated, cloned into pGEM-T-easy plasmid (Promega, Madison, WI, USA), and an average of 21.5 clones from each passage in each cell line were sequenced, using a 3130xl Genetic Analyzer (Applied Biosystems, Foster City, CA, USA). To determine mutation rates, sequences from all clones were compared with the sequence of the GFP gene in the parental vector using the neighbor-joining method in the ClustalX software and manual editing.

Recombinase-mediated cassette exchange

Master cell line cells were seeded onto six-well tissue culture plates at a density of $0.5 \times 10^{6}$ cells/plate in BHK complete medium without selective antibiotics. After $24 \mathrm{~h}$, cells were transfected with $0.5-4 \mu \mathrm{g}$ of pShuttle-SFV plasmid harboring the gene of interest mixed with $1 \mu \mathrm{g}$ of pBS185 CMV-Cre [29]. BHK complete medium containing $5 \mu \mathrm{g} / \mathrm{ml}$ puromycin was added to cells the following day and changed every third day. Cells were allowed to expand into sizable colonies for 3 days with puromycin before being harvested and transferred to new six-well dishes and subsequently expanded to T25 and T75 culture flasks. These parental cultures were induced with DOX to test heterologous protein expression, and the culture with best expression level was cloned by terminal dilution and expanded.

Analysis of heterologous protein expression

Whole-cell lysates were obtained by incubation of cells in a buffer containing $1 \%$ Igepal (Sigma, St. Louis, MO, USA), $50 \mathrm{mM}$ Tris-HCl pH 7.6, $150 \mathrm{mM} \mathrm{NaCl}, 2 \mathrm{mM}$ EDTA and $1 \mu \mathrm{g} / \mathrm{ml}$ PMSF (Sigma), and cleared by centrifugation for $6 \mathrm{~min}$ at $6,000 \mathrm{rpm}$ at $4^{\circ} \mathrm{C}$. For Western-blot experiments, supernatants and lysates from cells expressing heterologous proteins were analyzed by SDS-PAGE in $12 \%$ polyacrylamide gels, transferred to a nitrocellulose membrane, and incubated with the appropriate primary antibodies. These included rabbit polyclonal antiserum against GFP (Abcam, Cambridge, UK), actin (Sigma), or SFV nsp2 [13], a biotinylated goat polyclonal antiserum specific for human CT-1 (R\&D, Minneapolis, MN, USA), or a mouse monoclonal antibody specific for human OSM (R\&D Systems), peroxidase-conjugated goat-anti-rabbit antiserum (Pierce Biotechnology, Rockford, IL, USA), streptavidin-peroxidase polymer (Sigma), and peroxidase-conjugated goatanti-mouse (Pierce Biotechnology) antiserum were used 
as secondary antibodies, respectively. In all cases, proteins were visualized using the Western Lightning Chemiluminescence Reagent Plus (PerkinElmer Life Sciences, Waltham, MA, USA). Recombinant GFP (Cell Biolabs, Inc., San Diego, CA, USA), recombinant human CT-1 and OSM (R\&D Systems) produced in Escherichia coli were used as controls. The amount of CT1 and OSM present in supernatants from stable cell lines was quantified by a human CT-1-specific ELISA construction kit (ELISA Pair Set Kit RHF650CK, BioSupply, UK) and a human OSM specific ELISA kit (DSL-10-9400 Active Free, DSL, Webster, TX), respectively.

\section{Analysis of CT1 and OSM activities}

For testing human CT-1 activity, HepG2 cells were plated onto 12-well tissue plates at a density of $2 \times 10^{5}$ cells/ plate, grown for $24 \mathrm{~h}$ with $10 \% \mathrm{FBS}$, and then deprived of FBS for $48 \mathrm{~h}$. At this time, different amounts of CT-1 produced from stable cell lines or commercial recombinant CT-1 were added. Thirty minutes later, cell lysates were obtained and analyzed by Western blot with a rabbit antiserum specific for phosphorylated STAT3 (Cell Signalling, Danvers, MA, USA) and actin, using a peroxidase-conjugated sheep-anti-rabbit antiserum as secondary antibody in both cases. The same type of assay was used to test OSM activity but incubating Huh7 cells for $24 \mathrm{~h}$ in the presence of $10 \%$ FBS, depriving them of FBS for $48 \mathrm{~h}$ and adding different amounts of OSM produced from stable cell lines, using commercial recombinant human OSM as control. After $60 \mathrm{~min}$, lysates were obtained and analyzed by Western blot with rabbit antisera specific for phosphorylated STAT-3 and actin. Protein bands were visualized using the Western Lightning Chemiluminescence Reagent Plus, scanned with an ImageQuant ECL imager (GE Healthcare, Giles, UK) and quantitated with ImageQuant TL software (GE Healthcare).

Purification and biochemical characterization of OSM

A selected clone expressing OSM was incubated for $72 \mathrm{~h}$ at $33{ }^{\circ} \mathrm{C}$ with $\mathrm{BHK}$ complete medium containing $1.25 \mu \mathrm{g} /$ $\mathrm{ml}$ DOX and then, culture medium was replaced by EXCELL CHO medium for $24 \mathrm{~h}$. Culture media was collected and centrifuged at $1,000 \times g$ for $5 \mathrm{~min}$. Recombinant OSM was purified by affinity chromatography on a $\mathrm{Ni}^{2+}$-nitrilotriacetic column (QIAGEN, Germany) following the supplier's instructions and eluted with $125 \mathrm{mM}$ imidazol in an ÄKTA Explorer. The presence of recombinant protein was analyzed at each purification step by $12 \%$ SDS-PAGE followed by silver staining or Western blot as described earlier. The bands of interest were gel-digested with trypsin and protein identification was obtained by analysis of the digests in a coupled liquid chromatography and tandem mass spectrometry (LC-MS/MS).

Adaptation of adherent cell lines to suspension culture

Suspension cultures were initiated by pelleting trypsinized adherent cells and resuspending them in SMEM complete medium containing $10 \%$ FBS. Cells were incubated at $37{ }^{\circ} \mathrm{C}$ in spinner flasks under continuous agitation at $100 \mathrm{rpm}$. Cells were passaged every 3 days by diluting them at ratios between 1:3 and 1:5 in new medium. Growth rate and cell viability of the culture were monitored closely during the first 3 weeks of culture. Once the growth of the suspension culture was stabilized, serum was progressively eliminated by reducing its concentration in each passage by $50 \%$. For that purpose, medium in each passage was mixed 1:1 with serum-free medium (see above) until the serum concentration reached $0.5 \%$. At this point, cells were washed and grown in undiluted serum-free medium. This process took approximately 1 month.

\section{Results}

Generation of a stable cell line harboring an inducible noncytopathic SFV vector expressing GFP

A stable cell line harboring an inducible noncytophatic SFV replicon expressing GFP (i-ncSFV-GFP) was generated in two steps. First, BHK cells were transfected with a plasmid containing the trans-activator rtTA2sM2 (TA) gene [23] downstream of the phosphoglycerate kinase (PGK) promoter, followed by an IRES element and a gene conferring resistance to hygromycin (pPGK-TA-ires-Hyg, Fig. 1). Upon selection with hygromycin and expansion of a selected clone, a cell line was obtained (BHK-TA), which after addition of doxycycline (DOX), was able to transactivate expression of plasmids containing a reporter gene downstream of a tetracycline responsive element (tet $\mathrm{O}_{7}$ ) (data not shown). In a second step, BHK-TA cells were transfected with a plasmid containing the cDNA sequence of the ncSFV-GFP vector under the transcriptional control of a minimal albumin promoter (PAlb) [25] fused to tet $\mathrm{O}_{7}$ [23]. This plasmid also included a neomycin resistance gene downstream of the SV40 promoter (Fig. 1). The $5^{\prime}$ end of ncSFV was located at position 174 of PAlb, since we have determined in this study that this was the transcription starting point for this promoter (Supplementary Fig. 1). Placing the $5^{\prime}$ end of ncSFV at the starting point of transcription is extremely important for SFV replication [7]. After selection with neomycin, several clones were isolated by terminal dilution and analyzed for GFP expression with and without DOX. An optimal clone showing 
more than $80 \%$ of GFP-positive cells after induction and complete absence of leakage without DOX was chosen and expanded for further characterization. This clone was designated as the MCL.

Induction kinetics, temperature dependence, and stability of the MCL

The kinetics of MCL induction was measured by monitoring GFP and Rep expression after addition of DOX ( $2 \mu \mathrm{g} /$ $\mathrm{ml}$ ) at 33 and $37^{\circ} \mathrm{C}$, respectively. GFP-positive cells started to be visible after $24 \mathrm{~h}$ at $33{ }^{\circ} \mathrm{C}$, reaching around $90 \%$ of positive cells at $96 \mathrm{~h}$ (Fig. 2a, b). Surprisingly, induction at $37^{\circ} \mathrm{C}$ was not very efficient, with GFP cells starting to be visible at $48 \mathrm{~h}$ and resulting in a maximum of $40-50 \%$ of positive cells after $96 \mathrm{~h}$. The analysis of GFP expression by Western blot showed a very similar kinetics (Fig. 2c).
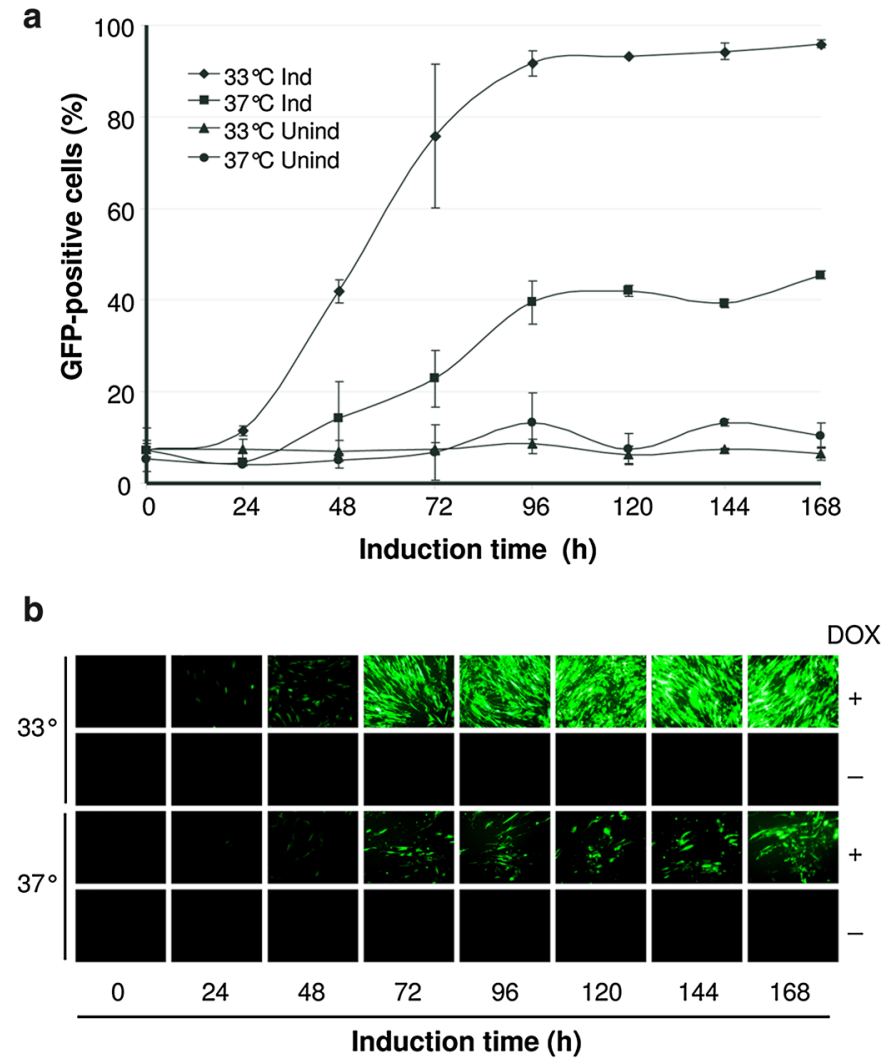

Fig. 2 Kinetics of GFP expression in the MCL. MCL cells were incubated with $2 \mu \mathrm{g} / \mathrm{ml}$ of DOX at 33 or $37^{\circ} \mathrm{C}$ and the presence of GFP-positive cells was analyzed at the indicated times by FACS (a) or with an inverted fluorescence microscope (b). Cells incubated without DOX were used as control. c Cell lysates were analyzed by Western blot with antibodies specific for GFP, Rep, and actin. Notice that for Rep panels, the part of the gel corresponding to $0-12 \mathrm{~h}$ was exposed five times longer than the one corresponding to 24-144 h

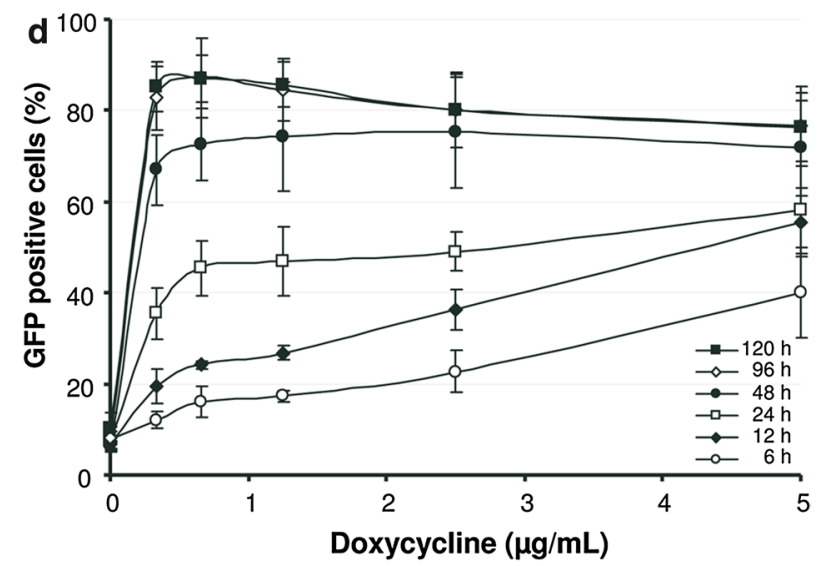

In contrast, the induction of Rep expression seemed to be quicker, being detectable at $12 \mathrm{~h}$ and reaching a maximum after $72 \mathrm{~h}$ of induction both at 33 and $37{ }^{\circ} \mathrm{C}$, although at much higher levels in the first case (Fig. 2c). A slight decrease in Rep expression was also observed after $72 \mathrm{~h}$ of incubation at $37^{\circ} \mathrm{C}$. ncSFV-GFP RNA levels increased an average of 4,632- and 289-fold after $72 \mathrm{~h}$ of induction at 33 and $37^{\circ} \mathrm{C}$, respectively (Supplementary Fig. 2). In order to optimize the induction conditions of the MCL, we analyzed the sensitivity of this cell line to different DOX concentrations and incubation times. This study showed that a maximum activation of GFP expression could be achieved with as low as $0.3 \mu \mathrm{g} \mathrm{DOX} / \mathrm{ml}$ if cells were incubated for at least 96 h (Fig. 2d). Shorter incubation times resulted in a lower percentage of GFP-positive cells even if DOX concentration was increased. To ensure maximum induction, subsequent experiments were usually performed using

C Time (h) after DOX addition

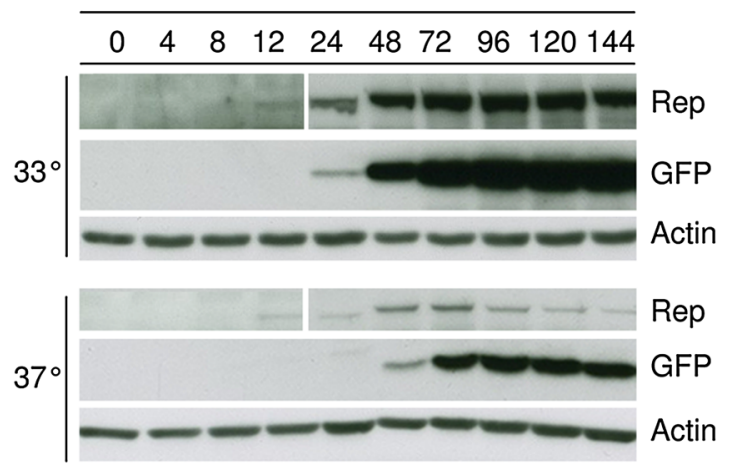

(d). The MCL was plated at a density of $5 \times 10^{5}$ cells per well in six-well plates. After $24 \mathrm{~h}$, cells were incubated with DOX at the indicated concentrations and times. After 5 days, the percentage of GFP-positive cells was analyzed by FACS. Results in a and $\mathbf{d}$ are the mean $\pm \mathrm{SD}$ values obtained from three independent experiments using passages 3,5, and 7. Results shown in $\mathbf{b}$ and $\mathbf{c}$ correspond to cells analyzed in passage 4 . Ind induced, Unind uninduced 
Fig. 3 Stability of GFP expression. The MCL was passaged 50 times every other day with or without selective antibiotics (neomycin and hygromycin, $\mathrm{Hyg} / \mathrm{Neo}$ ). At the indicated passages, cells were incubated for $120 \mathrm{~h}$ with $1.25 \mu \mathrm{g} / \mathrm{ml} \mathrm{DOX}$ (Ind.) or without DOX (Unind.) and GFP expression was evaluated by FACS (a) and Western blot with a specific antibody against GFP (b). ctrl stable cell line expressing GFP from an non-inducible RNA-based vector (ncSFV-pac2A-GFP) [21]
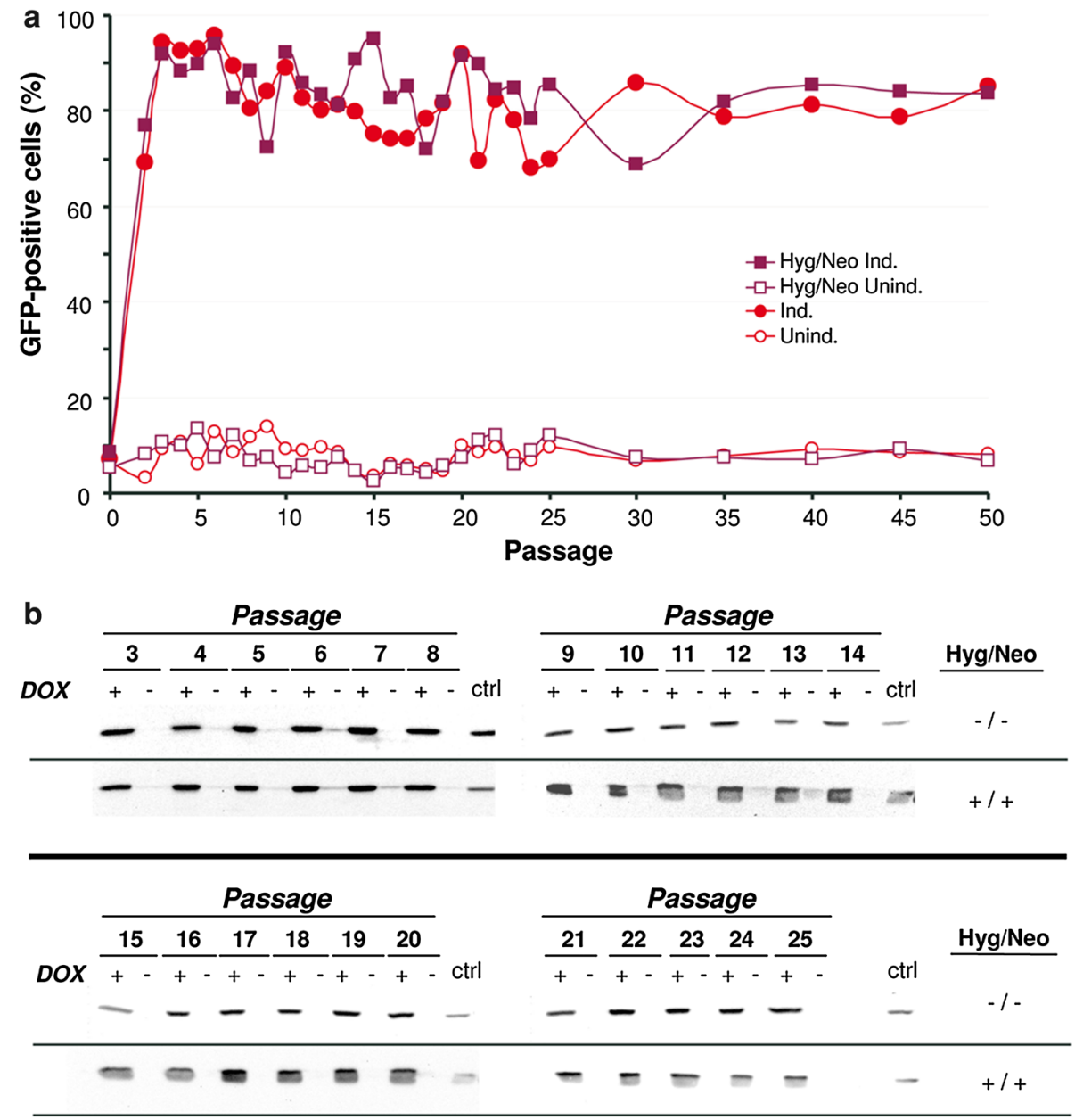

$1.25 \mu \mathrm{g} \mathrm{DOX} / \mathrm{ml}$ during $96 \mathrm{~h}$. Interestingly, removal of DOX in MCL cells that had been induced resulted in loss of GFP expression after 10 days (Supplementary Fig. 3a). However, cells that had lost GFP expression could be reinduced after DOX addition, indicating that induction is reversible (Supplementary Fig. 3b).

In order to evaluate the stability of the MCL, this cell line was passaged 50 times during a period of 5 months with or without the antibiotics previously used for selection (hygromycin and neomycin). The average duplication time for the MCL was $14.6 \mathrm{~h}$. The percentage of GFP-positive cells in each passage was assessed by FACS after DOX induction, showing that even after 50 passages $80-90 \%$ of cells could be induced (Fig. 3a). The high stability of the MCL was also confirmed by Western blot, which showed comparable levels of GFP in passages 1-25 (Fig. 3b). The fact that no differences in GFP expression were observed in cells cultured with or without selection antibiotics indicated that the MCL can be maintained in absence of selection.

Since the SFV Rep has not been reported to contain proof-reading activity, cells expressing the ncSFV-GFP vector could be prone to accumulate mutations in the
Table 1 Genetic stability of GFP RNA in the MCL

\begin{tabular}{lllll}
\hline Passage & Hyg/Neo & Mutated sequences & Mutations & Mutation rate \\
\hline 5 & + & $17 \%(4 / 24)$ & 4 & $2.6 \times 10^{-4}$ \\
15 & + & $0 \%(0 / 17)$ & 0 & $<9.0 \times 10^{-5}$ \\
20 & + & $0 \%(0 / 23)$ & 0 & $<6.6 \times 10^{-5}$ \\
25 & + & $4 \%(1 / 24)$ & 3 & $1.9 \times 10^{-4}$ \\
5 & - & $0 \%(0 / 21)$ & 0 & $<7.3 \times 10^{-5}$ \\
10 & - & $13 \%(2 / 16)$ & 2 & $1.8 \times 10^{-4}$ \\
17 & - & $4 \%(1 / 23)$ & 1 & $6.7 \times 10^{-5}$ \\
23 & - & $8 \%(1 / 24)$ & 2 & $1.3 \times 10^{-4}$ \\
\hline
\end{tabular}

a Percentage of mutated clones (\%). The number of mutated clones/ total number of analyzed clones is shown in brackets

b Total number of nucleotide changes in all clones analyzed from each passage

c Mutation rate was calculated by dividing the number of nucleotide changes in each passage by the total number of sequenced base pairs

heterologous gene. To analyze the genetic stability of the MCL, GFP cDNAs were obtained after DOX induction from four passages of the MCL maintained with or without 
Fig. 4 Kinetics of GFP expression in a conventional inducible cell line. A BHK stable cell line constitutively expressing rtTA2S-M2 transactivator and containing GFP gene under the transcriptional control of tetO7PAlb promoter was treated with $2 \mu \mathrm{g} / \mathrm{ml}$ of DOX or without DOX at $33{ }^{\circ} \mathrm{C}$. Cell lysates were analyzed at the indicated times by Western blot using an antibody against GFP and actin. MCL(+), MCL incubated during $120 \mathrm{~h}$ with DOX

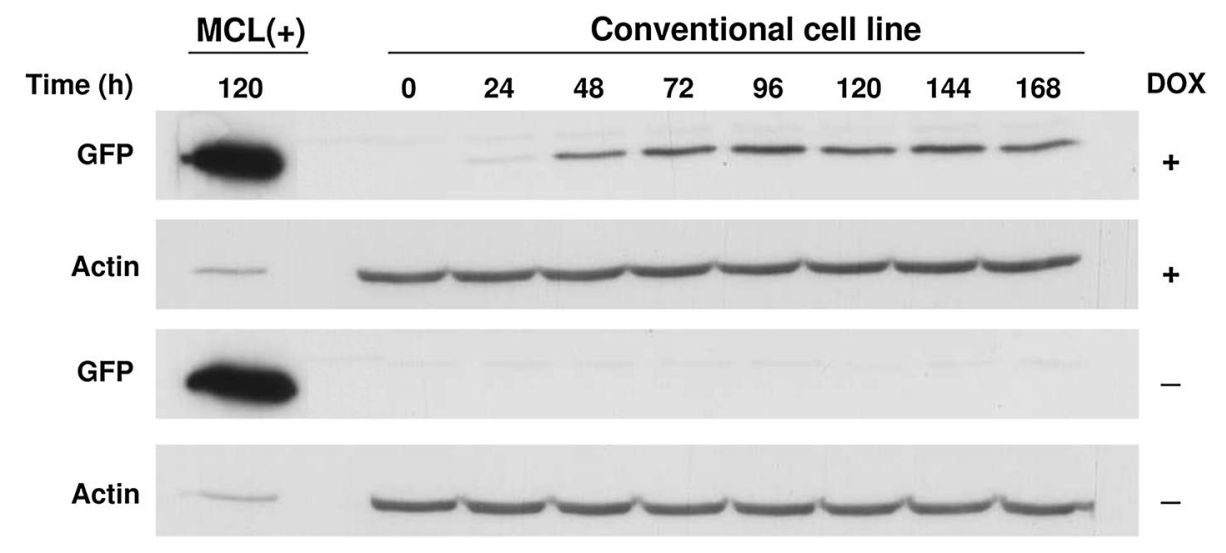

selective antibiotics. An average of 21.5 clones of each passage from each cell line were sequenced and compared to the parental sequence (Table 1). For each clone, a sequence corresponding to 660 nucleotides of GFP was obtained, which means that, on average, 14,190 nt were sequenced per passage in each cell line. Overall, a total of $113.5 \mathrm{~kb}$ were sequenced revealing the presence of very few mutations in the GFP gene, with an average mutation rate of $1 \times 10^{-4}$, which was lower than the mutation rate of the high-fidelity DNA polymerase used for this study. The mutation rate was independent of the passage, with several passages not showing any mutations. Furthermore, specific mutations that appeared at early passages did not accumulate.

Comparison of the MCL with a conventional inducible stable cell line

Transgene expression in the MCL is provided by a selfreplicating RNA vector, which should lead to higher expression levels than those obtained with a conventional stable cell line. In order to check if this was the case, we generated a control inducible cell line by transfecting BHK-TA cells with a plasmid containing the GFP gene under the transcriptional control of tet $\mathrm{O}_{7}$-PAlb promoter. After selection with neomycin, several clones were isolated by terminal dilution and analyzed for GFP expression with and without DOX. An optimal clone showing about $90 \%$ of GFP-positive cells after induction and complete absence of leakage without DOX was selected. In this clone, GFP-positive cells started to be visible $24 \mathrm{~h}$ after the addition of DOX, reaching around $90 \%$ of positive cells at $96 \mathrm{~h}$ (data not shown). Analysis of GFP expression by Western blot showed a very similar kinetics (Fig. 4). Importantly, GFP levels observed after induction were much lower than those obtained with the MCL (Fig. 4, compare GFP in the MCL and conventional cell lines after $120 \mathrm{~h}$ of DOX induction).
Generation of new stable cell lines

by recombinase-mediated transgene exchange

In order to generate new inducible cell lines in an easy and quick way, we designed a strategy to exchange both GFP and neomycin resistance genes in the MCL by Cremediated recombination with a DNA cassette containing the desired transgene and a new selection gene. For that purpose, mutant LoxP sites had been previously included in two positions of the integrated i-ncSFV-GFP-neo construct (Fig. 1). The first loxP site (LoxP1) was cloned between SFV subgenomic promoter and GFP, whereas the second LoxP site (LoxP2) was located between the neomycin ORF and its polyadenylation signal. LoxP1 and LoxP2 sites contain mutations that prevent Cre-mediated recombination between them (Supplementary Table 2) and allow unidirectional Cre-mediated recombination with LoxP sites containing complementary mutations [30, 31]. In order to introduce new transgenes into the MCL, a shuttle DNA vector was constructed (pShuttle-SFV), containing a multiple cloning site, where a new heterologous gene can be cloned, followed by the SFV $3^{\prime}$-end, and a gene conferring resistance to puromycin (pac) without a polyA signal (Fig. 5a). This cassette was flanked by LoxP sites (LoxP3 and LoxP4) that also contained mutations that impair recombination between them and allow unidirectional Cre-mediated recombination with LoxP1 and LoxP2, respectively (Supplementary Table 2). In order to test this approach, we generated a pSFV-shuttle vector containing the gene expressing red fluorescent protein Tomato (pShuttle-SFV-Tomato). The MCL was cotransfected with pShuttle-SFV-Tomato and a plasmid expressing Cre recombinase (pCMV-CRE), and $24 \mathrm{~h}$ later puromycin was added to a final concentration of $5 \mu \mathrm{g} / \mathrm{ml}$. As it can be observed by fluorescence microscopy, a puromycin-resistant cell population was obtained in which a high proportion of cells were now able to express Tomato after DOX induction, with no GFP-expressing cells (Fig. 5b). The observation that in this 


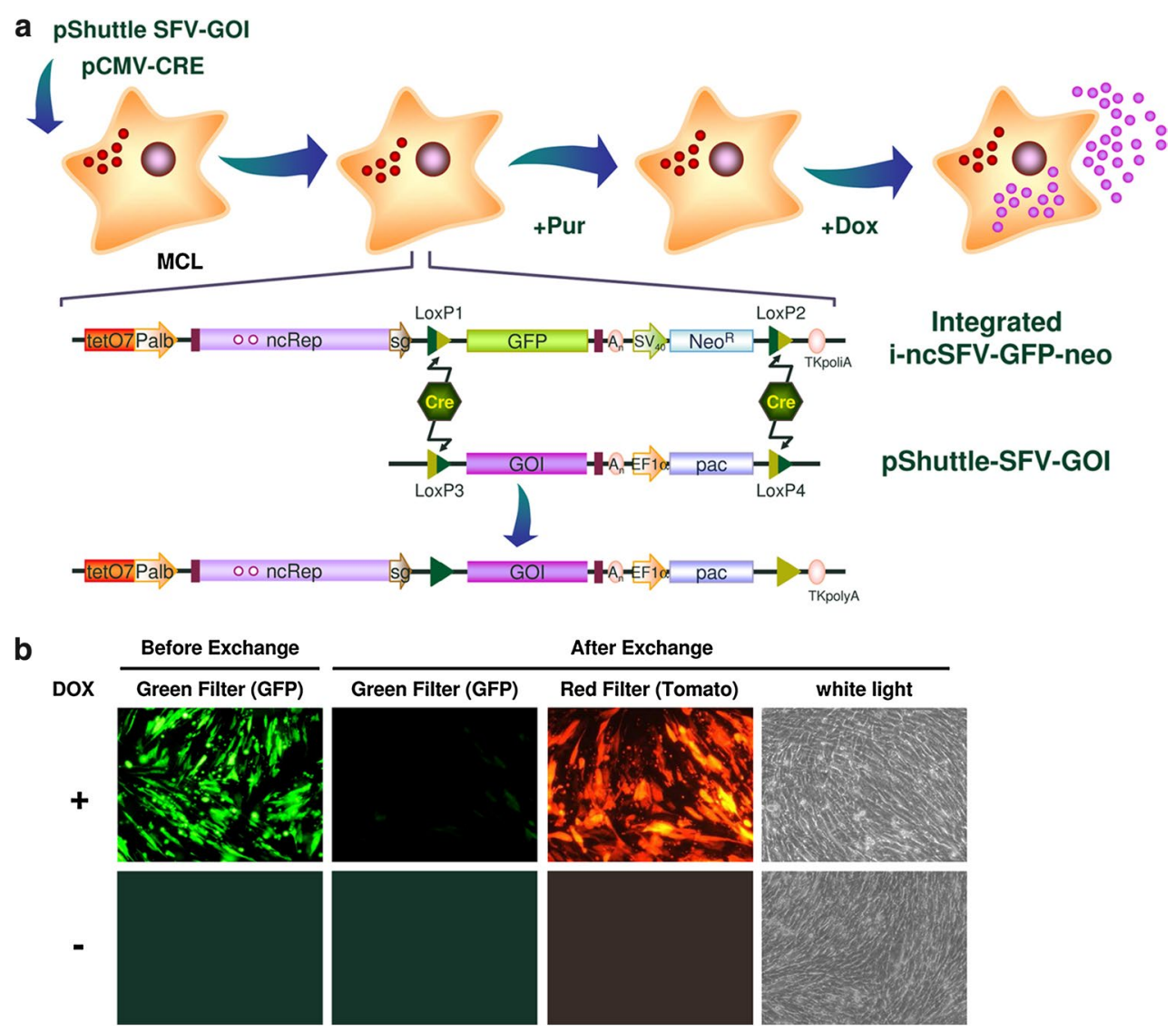

Fig. 5 Recombinase-mediated cassette exchange. a Schematic diagram of new cell lines' selection process. In order to generate a stable cell line expressing a gene of interest (GOI), the MCL is cotransfected with a plasmid coding Cre recombinase (pCMV-CRE) and a shuttle vector harboring the GOI and the puromycin resistance gene pac (pShuttle-SFV-GOI). After Cre-mediated recombination the GFP-Neo ${ }^{\mathrm{R}}$ cassette is substituted by GOI-pac, and cells become sensitive to neomycin and resistant to puromycin, which can be used to

population some cells were resistant to puromycin but did not express Tomato, indicates that correct recombination did not take place in $100 \%$ of cells (compare pictures taken with red filter or white light). In spite of this, the fact that a high proportion of cells can express the new transgene after induction can greatly facilitate the selection and amplification of individual clones.

Generation of stable cell lines expressing human CT-1

In order to validate if our inducible cell lines could be used for production of clinically relevant proteins, the human CT-1 gene was cloned into the pShuttle-SFV vector fused to a signal peptide and including a 6-histidine-tag (His-tag) at its amino-terminal end (pShuttle-SFV-CT, Fig. 6a). This vector was cotransfected with $\mathrm{pCMV-CRE}$ into the MCL and at $24 \mathrm{~h}$ post-transfection puromycin was added at $5 \mu \mathrm{g} /$ ml. After selection, a batch culture was induced with DOX select the new cell lines. b Evaluation of transgene exchange using Tomato as GOI. The MCL was cotransfected with $1 \mu \mathrm{g}$ of pCMV$\mathrm{CRE}$ and $2 \mu \mathrm{g}$ of the pShuttle-SFV-Tomato. After $24 \mathrm{~h}$, puromycin was added to a final concentration of $5 \mu \mathrm{g} / \mathrm{ml}$ and selection was performed in batch until confluence. Once selected, the new cell line was induced with DOX at a final concentration of $1.25 \mu \mathrm{g} / \mathrm{ml}$ during 5 days, and evaluated for GFP and Tomato expression with a fluorescence microscope. EF $\alpha$ elongation factor-1 alpha promoter

and CT- 1 expression in the supernatant was confirmed by Western blot (data not shown). Selected cells were cloned by terminal dilution and three clones showing high CT-1 expression after induction (CT1-A, -CT1-B, and CT1-C) were expanded and characterized. CT- 1 produced by these clones showed a size that was slightly larger than that of recombinant CT-1 expressed in bacteria, indicating that most likely the protein was glycosylated (Fig. 6b), as previously shown [21]. To determine the kinetics of CT-1 expression, selected clones were induced during 5 days with DOX, supernatants were collected every $24 \mathrm{~h}$ and secreted CT-1 was measured by specific ELISA. CT-1 concentration increased drastically after $24 \mathrm{~h}$ of induction in the three clones, reaching a concentration of approximately $3 \mathrm{mg} / \mathrm{l} / 24 \mathrm{~h}$ after $120 \mathrm{~h}$ (Supplementary Fig. 4a). One of the clones (CT-1A) was also analyzed by RT-PCR to verify correct transgene exchange (Supplementary Fig. 5). The stability of selected clones was studied by passaging 


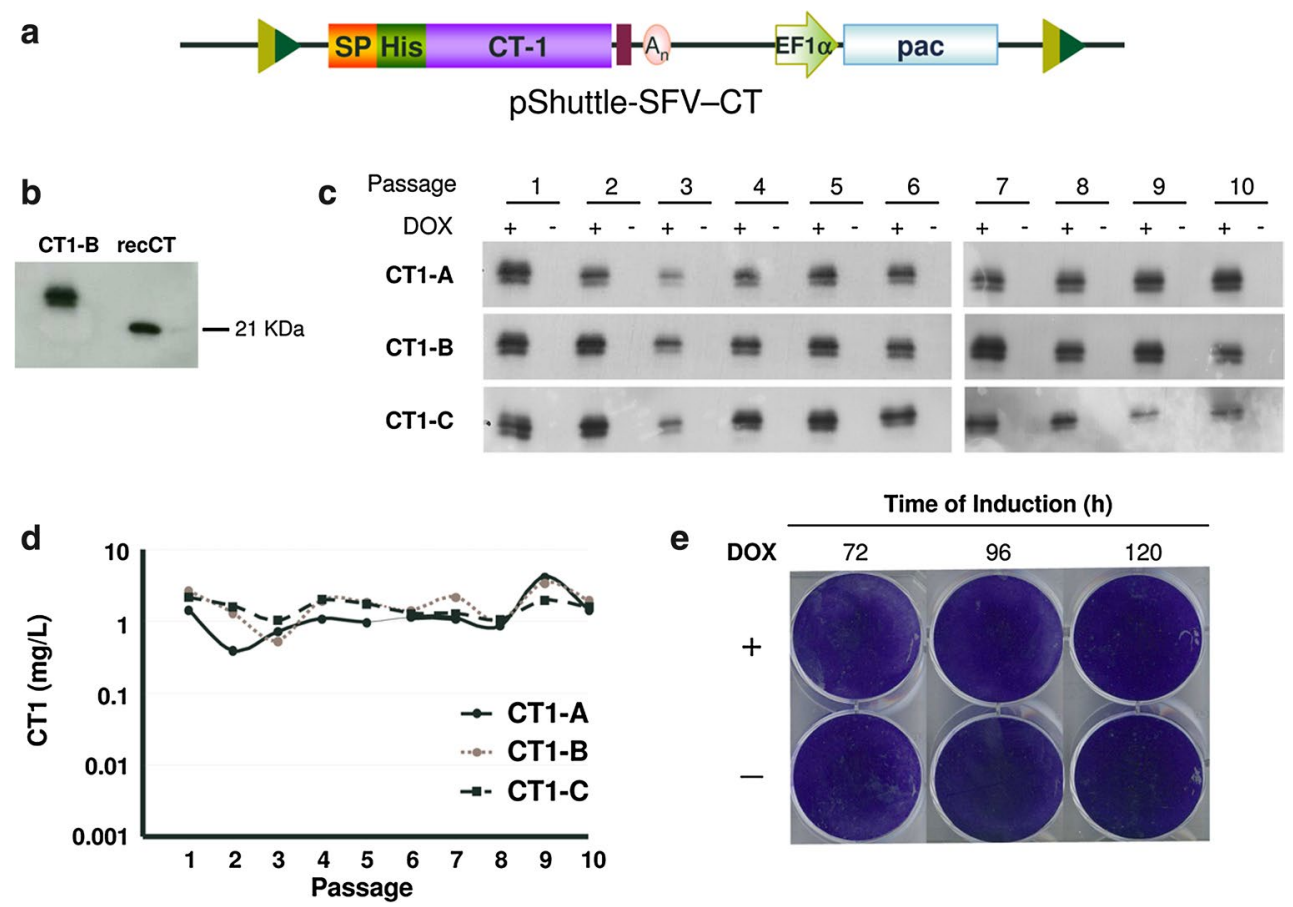

Fig. 6 Generation and characterization of stable cell lines expressing human cardiotrophin-1 (CT-1). a Diagram of pShuttle-SFV vector harboring the sequence of human CT-1 gene (pShuttle-SFV-CT). In this vector, CT- 1 is fused in frame with the preprotrypsin signal peptide (SP) and a sequence coding for a six histidine-tag (His) at the amino-terminal end. b Analysis of CT-1 expression in the supernatant of clone CT1-B after DOX induction by Western blot with an antiserum specific for CT-1, using as control recombinant CT-1 pro-

duced in bacteria (recCT). c, d Analysis of CT-1 expression in three selected clones obtained after Cre-mediated cassette exchange. CT1 clones were passaged ten times in the absence of selective antibiotics and CT-1 expression was analyzed in supernatants collected $120 \mathrm{~h}$ after induction with DOX, or without induction, by Western blot as described in b (c) and specific CT-1 ELISA (d). e Cytotoxicity after protein expression was assessed by crystal violet staining at the indicated times using clone CT1-A

them ten times in the absence of puromycin for a period of 30 days and analyzing CT- 1 expression by Western blot and ELISA after induction in each passage. The three clones showed a very high stability, maintaining CT-1 levels of $1-5 \mathrm{mg} / \mathrm{l}$ in all analyzed passages with no leakage in the absence of induction (Fig. 6c, d). The functional activity of recombinant CT-1 present in supernatants of each clone was evaluated by their capacity to induce STAT3 phosphorylation on HepG2 cells that had been deprived of FBS during $48 \mathrm{~h}$ (Supplementary Fig. 4B, only CT1-A is shown). All supernatants induced STAT3 phosphorylation with a specific activity that was similar to that of commercial CT-1.

Generation and characterization of stable cell lines expressing human oncostatin $\mathrm{M}$

OSM, a cytokine of the interleukin-6 family with potential antitumor and antiviral properties [22], has been reported to inhibit growth of numerous tumor cell lines [32]. This inhibitory effect has also been observed by us in cell lines commonly used for protein production, like BHK cells, which hampers the production of this protein

(Supplementary Fig. 6). One important advantage of our inducible ncSFV expression system is that it could be used to express proteins that are toxic for producing cells, since these cells could be grown to the desired amount before expression is induced. In order to test this hypothesis, the gene coding for the mature form of human OSM was cloned into the pShuttle-SFV vector as described in "Materials and methods", generating the pShuttle-SFVOSM plasmid (Fig. 7a). This vector was cotransfected with pCMV-CRE into the MCL and at $24 \mathrm{~h}$ post-transfection, puromycin was added at $5 \mu \mathrm{g} / \mathrm{ml}$. After selection in batch, the culture was induced with DOX and OSM expression in the supernatant was confirmed by Western blot, indicating that even though this protein is toxic for BHK cells, it can be expressed (data not shown). Selected cells were cloned by terminal dilution and three clones showing high OSM expression after induction (OSM-A, OSM-B and OSM-C) were expanded and further characterized. OSM produced by these clones showed a size that was slightly higher than that of recombinant OSM expressed in bacteria, indicating that most likely the protein was glycosylated (Fig. 7b). To determine the kinetics of OSM expression, selected clones were induced during 5 days with DOX, supernatants were 


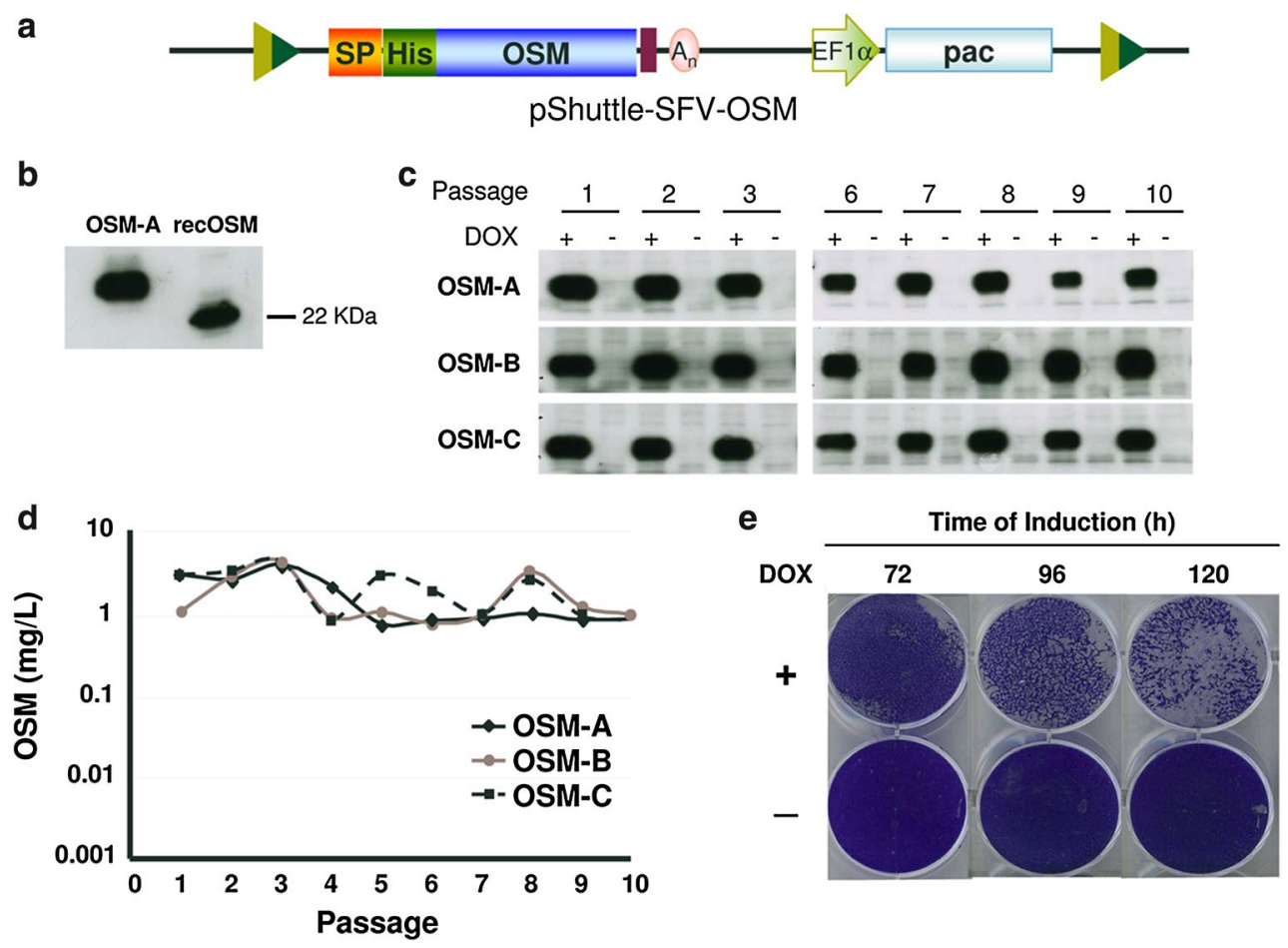

Fig. 7 Generation and characterization of stable cell lines expressing human Oncostatin M (OSM). a Diagram of pShuttle vector harboring the sequence of the OSM gene fused in frame with the preprotrypsin signal peptide (SP) and a histidine-tag (His) at the amino-terminal end (pShuttleSFV-OSM). b Analysis of OSM expression in the supernatant of clone OSM-A after DOX induction by Western blot with an antiserum specific for OSM, using as control recombinant OSM produced in bacteria (recOSM). c, $\mathbf{d}$ Analysis of OSM expression in

collected every $24 \mathrm{~h}$, and secreted OSM was measured by specific ELISA. Since BHK cells are sensitive to OSM, $72 \mathrm{~h}$ after induction cell cultures showed a strong cytopathic effect and formed aggregates that were not present in uninduced cells or in cells expressing CT-1 (Fig. 7e, 6e). OSM concentration increased progressively after induction in the three clones, reaching a maximum level after $96 \mathrm{~h}$ of approximately $1 \mathrm{mg} / \mathrm{l} / 24 \mathrm{~h}$ (Supplementary Fig. 4c). One of the clones (OSM-A) was also analyzed by RT-PCR to verify correct transgene exchange (Supplementary Fig. 5). The stability of selected clones was studied by passaging them ten times in the absence of puromycin for a period of 30 days and analyzing OSM expression by ELISA and Western blot after induction of each passage. As observed with cell lines expressing CT-1, the three OSM clones showed very high stability, maintaining levels of $1-8 \mathrm{mg} \mathrm{OSM} / \mathrm{l} / 24 \mathrm{~h}$ in all analyzed passages with no leakage in the absence of induction (Fig. 7c, d). The functional activity of recombinant OSM produced by selected clones was also evaluated by its capacity to induce STAT3 phosphorylation on Huh7 cells that had been deprived of three selected clones. OSM clones were passaged ten times in the absence of selective antibiotics and OSM expression was analyzed in supernatants collected $96 \mathrm{~h}$ after induction with DOX, or without induction, by Western blot as described in $\mathbf{b}(\mathbf{c})$ and specific ELISA (d). e Cytotoxicity after OSM expression was assessed by crystal violet staining at the indicated times using clone OSM-A. A clear cytopathic effect was observed only in cells incubated with DOX

FBS during $48 \mathrm{~h}$. Supernatants from each clone contained active OSM (Supplementary Fig. 4d, only OSM-A is shown), confirming that the i-ncSFV system can be used to generate cell lines that express toxic proteins at high levels with high stability and maintaining their biological activity.

Purification and characterization of human OSM expressed from SFV cell lines

To purify OSM, clone OSM-A was grown to a final quantity of approximately $10^{8}$ cells and incubated with $100 \mathrm{ml}$ of the medium supplemented with DOX during 3 days. At this time, medium was replaced by new medium without serum and $24 \mathrm{~h}$ later OSM was purified from the supernatant by using a $\mathrm{Ni}^{2+}$-nitrilotriacetic column (QIAGEN, Germany) as described in "Materials and methods". A yield of $1.54 \mathrm{mg} / \mathrm{l}$ of highly pure OSM was obtained with an average recovery of $43 \%$. Protein identity was confirmed by coupled liquid chromatography and tandem mass spectrometry (LC-MS/MS). Biological activity of purified 


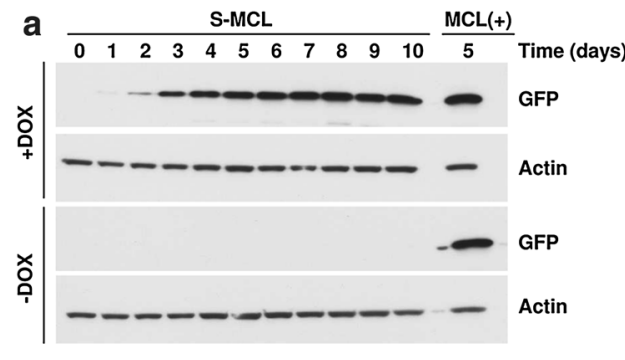

Fig. 8 Kinetics of expression in cell lines adapted to growth in suspension. a The MCL was adapted to grow in suspension (S-MCL), cells were incubated with $2 \mu \mathrm{g} / \mathrm{ml}$ of DOX or without DOX at $33{ }^{\circ} \mathrm{C}$ and expression of GFP was analyzed in cell lysates at the indicated times by Western blot. MCL(+), adherent MCL cells incubated during 5 days with DOX used as control. b OSM-A cell line adapted to

OSM was assessed by measuring STAT3 phosphorylation, as described above (Supplementary Fig. 7). Purified OSM showed a similar activity to commercial recombinant protein produced in bacteria.

\section{Adaptation of inducible selected cell lines to grow as a serum-free suspension-adapted lineage}

Suspension cultures growing in the absence of serum are highly desirable for biotechnological processes. For that reason we evaluated the possibility of adapting adherent i-ncSFV cell lines to grow under these conditions. The adaptation process involved two phases. In the first phase, suspension cultures of selected cell lines (MCL and clone OSM-A) were initiated by cultivating trypsinized cells in spinner flasks with growth medium especially formulated for suspension cultures and in the presence of $10 \%$ FBS. After approximately 3 weeks, both cell lines were adapted to grow in suspension. These suspension cell lines were able to express levels of GFP and OSM after DOX induction that were comparable to those expressed by their parental adherent cell lines (Fig. 8a, b). The OSM suspension cell line was able to express high levels of OSM during at least 10 days, in spite of the growth inhibition shown by this protein on adherent BHK cells. In the second phase, this suspension cell line was subject to a series of steps in which FBS concentration was progressively reduced until its complete elimination. OSM cell lines adapted to growth in suspension with or without FBS showed similar OSM levels during the first 4 days of induction (Fig. 8b). However, after day 4 these levels increased in the presence of FBS reaching $3 \mathrm{mg} / \mathrm{l} / 24 \mathrm{~h}$, while in the absence of FBS they were maintained at an average level of $0.26 \mathrm{mg} / \mathrm{l} / 24 \mathrm{~h}$, suggesting that OSM toxicity could be higher in the absence of FBS (Fig. 8b).

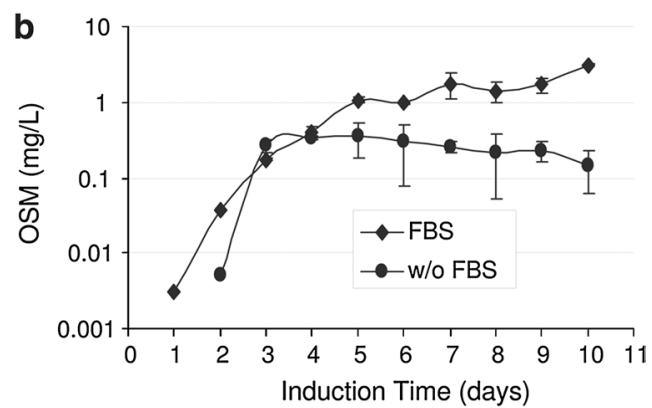

grow in suspension with serum (FBS), or without serum (w/o FBS) were induced with DOX as described, medium was replaced by new medium every $24 \mathrm{~h}$ and OSM expression in the supernatant was evaluated by specific ELISA at the indicated times. The curve represents mean values $\pm \mathrm{SD}$

\section{Discussion}

In the present study, we have generated a new type of stable cell line based on a self-amplifying RNA that is transcribed in an inducible way, leading to very high expression levels. Using this system, we have also developed a platform that allows for a quick generation of new stable cell lines based on directed transgene exchange mediated by Cre recombinase from an initially characterized MCL.

The use of an alphavirus DNA/RNA layered system offers some important advantages compared to conventional stable cell lines. One of them is the avoidance of chromosomal integration position effects, since once replication is established, mRNAs coding for the protein of interest will accumulate independently of initial transcription levels. In this regard, the generation of this type of inducible system requires a very low basal level of transcription in the absence of inducer, since only a few molecules of RNA replicon could be sufficient to trigger replication. In order to reduce leakiness, we used a minimal promoter that had shown very low transcriptional activity in previous studies [25]. In spite of that, some of the initially selected clones with integrated i-nc-SFV-GFP vectors showed high GFP expression in the absence of DOX (data not shown), probably due to integration site effects. However, we were able to isolate one clone (MCL), out of 17 analyzed clones, that showed an almost undetectable leakage by fluorescence microscopy, Western blot, and PCR. Most importantly, ncSFV RNA levels in the MCL increased $>4,600$-fold after 3 days of induction. This level of inducibility is much higher than the one described for DOX inducible systems [33], which is probably due to the self-replication nature of the SFV RNA. In fact, when we compared the MCL with a conventional cell line in which GFP expression was regulated by the same induction 
system, expression levels were much higher in the first case (Fig. 4).

Interestingly, the induction of the MCL was strongly temperature sensitive, requiring incubation at $33{ }^{\circ} \mathrm{C}$ for optimal GFP expression (Fig. 2a-c). The lower GFP expression observed after induction at $37{ }^{\circ} \mathrm{C}$ seemed to be the result of lower vector RNA replication at this temperature (Supplementary Fig. 2). In agreement with these results, it has been reported that BHK cells infected or transfected with SFV cytopathic and non-cytopathic vectors are able to express higher levels of recombinant proteins when cultured at $31-33{ }^{\circ} \mathrm{C}$ compared to $37{ }^{\circ} \mathrm{C}$ [14, $15,34]$.

The master cell line showed a very high stability, with no apparent loss of expression after 50 passages in culture. One concern when using alphavirus vectors is the possible accumulation of mutations, due to the fact that SFV Rep does not contain proof-reading activity. In spite of that, we detected a very small number of mutations in GFP RNA sequences derived from the MCL induced at different passages. The observed mutation rate $\left(10^{-4}\right)$ was lower than the one observed in our previously described cell lines based on a self-replicating RNA [21], suggesting that by avoiding continuous RNA replication we can limit the incorporation of mutations. Furthermore, the observed mutation rate was lower than the one described for the high-fidelity DNA polymerase used for this study, indicating that some of the detected mutations could in fact not be present in the GFP RNA.

Given the favorable features of the MCL, we have used it as a platform for the generation of new cell lines based on transgene switch mediated by Cre recombinase. For that purpose, we flanked the sequence comprising the transgene and selection genes with LoxP sites that combine mutations described to mediate irreversible [30] and unidirectional recombination [31]. This strategy was successfully used to exchange the GFP gene in the MCL by the Tomato, CT-1, and OSM genes. In all cases transgene exchange was accompanied by the substitution of the neomycin resistance gene by the pac gene. Although the efficiency of this process varied with the ratio of transgene/Cre plasmids used to transfect the MCL (data not shown), optimal conditions led to a high proportion of cells that upon selection had switched both transgenes. This made the generation of new stable cell lines an easy and quick process, since analysis of only a few clones was sufficient to obtain cell lines expressing the desired proteins at levels that reached 5 and $8 \mathrm{mg} / \mathrm{l} / 24 \mathrm{~h}$ for CT- 1 and OSM, respectively. Most importantly, the new cell lines maintained the inducibility and stability of the MCL, most likely because in these cells the ncSFV vector remained integrated in the same position as in the MCL. One of the main advantages of the inducible stable cell lines described in this work is the possibility to use them for expression of proteins that are toxic or negatively affect proliferation of cells, as is the case of OSM expression in BHK cells. The complete lack of OSM expression in the absence of the inducer allowed us to grow cells containing the ncSFV-OSM vector to the desired amount, and produce high amounts of recombinant OSM after DOX induction. Previously, an inducible Sindbis DNA/RNA layered system regulated by temperature has also been described [35]. With this system it was possible to express both $\beta$-interferon and the apoptosis-inducing death domain of the RIP protein (RipDD), which is a toxic protein, at high levels in BHK stable cell lines. These cells constitutively expressed a non-active noncytopathic Rep, which became functional after temperature switch, leading to vector replication and transgene expression. In contrast to this system, our i-ncSFV based cell lines do not express Rep in the absence of induction (Fig. 2c), which could favor the growth of these cells. In fact, the MCL showed an average division time of $14.6 \mathrm{~h}$ in the absence of DOX, which was similar to that of parental BHK (data not shown). In addition, absence of Rep expression without DOX could allow these cells to produce SFV replicons carrying wt Rep, which is cytopathic for mammalian cells. These SFV replicons could be packaged into viral particles by providing helper RNAs expressing SFV capsid and envelope proteins in trans [36], or by expressing these proteins from inducible promoters in the same cells. Since cytopathic alphavirus vectors have shown a great potential for vaccination and cancer gene therapy, the cell lines described in this work could also be attractive for this field [37].

Finally, the fact that MCL-derived cells were easily adapted to growth in suspension and in the absence of FBS, makes this new system very attractive for the production of human therapeutic proteins that require appropriate posttranslational modifications, and especially for those proteins that are toxic or difficult to produce with non-inducible systems.

Acknowledgments This work was financed by 3P Biopharmaceuticals S. L. (Noain, Spain). We would like to acknowledge expert and technical assistance from the following personnel from CIMA (Pamplona, Spain): Juan Jose Lasarte for help with protein purifications, Fernando Corrales and Carmen Miqueo for LC-MS/MS analysis, Ana Patiño, Arancha Bielsa, and Ursula Bubea for sequencing. We also want to thank Edita Mistiniene (3P Biopharmaceuticals S.L.) for fruitful discussions and the Center for Applied Medical ResearchUTE Project for supporting this project. A. A. was the recipient of a Torres Quevedo contract.

\section{References}

1. Wurm FM (2004) Production of recombinant protein therapeutics in cultivated mammalian cells. Nat Biotechnol 22(11):1393-1398 
2. Wurm F, Bernard A (1999) Large-scale transient expression in mammalian cells for recombinant protein production. Curr Opin Biotechnol 10(2):156-159

3. Liljestrom P, Garoff H (1991) A new generation of animal cell expression vectors based on the Semliki Forest virus replicon. Biotechnology (NY) 9(12):1356-1361

4. Pushko P, Parker M, Ludwig GV, Davis NL, Johnston RE, Smith JF (1997) Replicon-helper systems from attenuated Venezuelan equine encephalitis virus: expression of heterologous genes in vitro and immunization against heterologous pathogens in vivo. Virology 239(2):389-401

5. Xiong C, Levis R, Shen P, Schlesinger S, Rice CM, Huang HV (1989) Sindbis virus: an efficient, broad host range vector for gene expression in animal cells. Science 243(4895):1188-1191

6. Strauss JH, Strauss EG (1994) The alphaviruses: gene expression, replication, and evolution. Microbiol Rev 58(3):491-562

7. Berglund P, Smerdou C, Fleeton MN, Tubulekas I, Liljestrom P (1998) Enhancing immune responses using suicidal DNA vaccines. Nat Biotechnol 16(6):562-565

8. Frolov I, Schlesinger S (1994) Comparison of the effects of Sindbis virus and Sindbis virus replicons on host cell protein synthesis and cytopathogenicity in BHK cells. J Virol 68(3):1721-1727

9. Glasgow GM, McGee MM, Sheahan BJ, Atkins GJ (1997) Death mechanisms in cultured cells infected by Semliki Forest virus. J Gen Virol 78(Pt 7):1559-1563

10. Lundstrom K (1997) Alphaviruses as expression vectors. Curr Opin Biotechnol 8(5):578-582

11. Frolov I, Agapov E, Hoffman TA Jr, Pragai BM, Lippa M, Schlesinger S, Rice CM (1999) Selection of RNA replicons capable of persistent noncytopathic replication in mammalian cells. J Virol 73(5):3854-3865

12. Perri S, Driver DA, Gardner JP, Sherrill S, Belli BA, Dubensky TW Jr, Polo JM (2000) Replicon vectors derived from Sindbis virus and Semliki forest virus that establish persistent replication in host cells. J Virol 74(20):9802-9807

13. Casales E, Rodriguez-Madoz JR, Ruiz-Guillen M, Razquin N, Cuevas Y, Prieto J, Smerdou C (2008) Development of a new noncytopathic Semliki Forest virus vector providing high expression levels and stability. Virology 376(1):242-251

14. Lundstrom K, Abenavoli A, Malgaroli A, Ehrengruber MU (2003) Novel Semliki Forest virus vectors with reduced cytotoxicity and temperature sensitivity for long-term enhancement of transgene expression. Mol Ther 7(2):202-209

15. Lundstrom K, Rotmann D, Hermann D, Schneider EM, Ehrengruber MU (2001) Novel mutant Semliki Forest virus vectors: gene expression and localization studies in neuronal cells. Histochem Cell Biol 115(1):83-91

16. Tamm K, Merits A, Sarand I (2008) Mutations in the nuclear localization signal of nsP2 influencing RNA synthesis, protein expression and cytotoxicity of Semliki Forest virus. J Gen Virol 89(Pt 3):676-686

17. Petrakova O, Volkova E, Gorchakov R, Paessler S, Kinney RM, Frolov I (2005) Noncytopathic replication of Venezuelan equine encephalitis virus and eastern equine encephalitis virus replicons in Mammalian cells. J Virol 79(12):7597-7608

18. Aranda A, Ruiz-Guillen M, Quetglas JI, Bezunartea J, Casales E, Smerdou C (2011) Recent patents on alphavirus protein expression and vector production. Recent Pat Biotechnol 5(3):212-226

19. Ryan MD, Drew J (1994) Foot-and-mouth disease virus 2A oligopeptide mediated cleavage of an artificial polyprotein. EMBO J 13(4):928-933

20. Iniguez $M$, Berasain $C$, Martinez-Anso E, Bustos M, Fortes $P$, Pennica D, Avila MA, Prieto J (2006) Cardiotrophin-1 defends the liver against ischemia-reperfusion injury and mediates the protective effect of ischemic preconditioning. J Exp Med 203(13):2809-2815
21. Casales E, Aranda A, Quetglas JI, Ruiz-Guillen M, RodriguezMadoz JR, Prieto J, Smerdou C (2010) A novel system for the production of high levels of functional human therapeutic proteins in stable cells with a Semliki Forest virus noncytopathic vector. New Biotechnol 27(2):138-148

22. Larrea E, Aldabe R, Gonzalez I, Segura V, Sarobe P, Echeverria I, Prieto J (2009) Oncostatin M enhances the antiviral effects of type I interferon and activates immunostimulatory functions in liver epithelial cells. J Virol 83(7):3298-3311

23. Urlinger S, Baron U, Thellmann M, Hasan MT, Bujard H, Hillen W (2000) Exploring the sequence space for tetracycline-dependent transcriptional activators: novel mutations yield expanded range and sensitivity. Proc Natl Acad Sci USA 97(14):7963-7968

24. Vanrell L, Di Scala M, Blanco L, Otano I, Gil-Farina I, Bal$\operatorname{dim}$ V, Paneda A, Berraondo P, Beattie SG, Chtarto A, Tenenbaum L, Prieto J, Gonzalez-Aseguinolaza G (2011) Development of a liver-specific Tet-on inducible system for AAV vectors and its application in the treatment of liver cancer. Mol Ther 19(7):1245-1253

25. Kramer MG, Barajas M, Razquin N, Berraondo P, Rodrigo M, Wu C, Qian C, Fortes P, Prieto J (2003) In vitro and in vivo comparative study of chimeric liver-specific promoters. Mol Ther 7(3):375-385

26. Berraondo P, Ochoa L, Crettaz J, Rotellar F, Vales A, MartinezAnso E, Zaratiegui M, Ruiz J, Gonzalez-Aseguinolaza G, Prieto J (2005) IFN-alpha gene therapy for woodchuck hepatitis with adeno-associated virus: differences in duration of gene expression and antiviral activity using intraportal or intramuscular routes. Mol Ther 12(1):68-76

27. de la Luna S, Soria I, Pulido D, Ortin J, Jimenez A (1988) Efficient transformation of mammalian cells with constructs containing a puromycin-resistance marker. Gene 62(1):121-126

28. Linsley PS, Kallestad J, Ochs V, Neubauer M (1990) Cleavage of a hydrophilic C-terminal domain increases growth-inhibitory activity of oncostatin M. Mol Cell Biol 10(5):1882-1890

29. Sauer B, Henderson N (1990) Targeted insertion of exogenous DNA into the eukaryotic genome by the Cre recombinase. New Biol 2(5):441-449

30. Arakawa H, Lodygin D, Buerstedde JM (2001) Mutant loxP vectors for selectable marker recycle and conditional knock-outs. BMC Biotechnol 1:7

31. Lee G, Saito I (1998) Role of nucleotide sequences of loxP spacer region in Cre-mediated recombination. Gene 216(1):55-65

32. Horn D, Fitzpatrick WC, Gompper PT, Ochs V, Bolton-Hansen M, Zarling J, Malik N, Todaro GJ, Linsley PS (1990) Regulation of cell growth by recombinant oncostatin M. Growth Factors 2(2-3):157-165

33. Rossi FM, Blau HM (1998) Recent advances in inducible gene expression systems. Curr Opin Biotechnol 9(5):451-456

34. Ansorena E, Casales E, Aranda A, Tamayo E, Garbayo E, Smerdou C, Blanco-Prieto MJ, Aymerich MS (2013) A simple and efficient method for the production of human glycosylated glial cell line-derived neurotrophic factor using a Semliki Forest virus expression system. Int J Pharm 440(1):19-26

35. Boorsma M, Nieba L, Koller D, Bachmann MF, Bailey JE, Renner WA (2000) A temperature-regulated replicon-based DNA expression system. Nat Biotechnol 18(4):429-432

36. Smerdou C, Liljestrom P (1999) Two-helper RNA system for production of recombinant Semliki forest virus particles. J Virol 73(2):1092-1098

37. Quetglas JI, Ruiz-Guillen M, Aranda A, Casales E, Bezunartea J, Smerdou C (2010) Alphavirus vectors for cancer therapy. Virus Res 153(2):179-196 